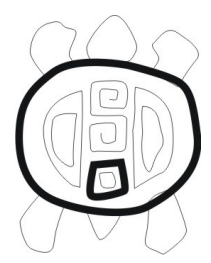

RMA

Antropología Social

\title{
Las chicas en la casa, los chicos en la calle. Construcción genérica, violencia y prácticas de sociabilidad en Villa el Nailon, Córdoba
}

María Elena Previtali

CONICET-Museo de Antropología, Facultad de Filosofía y Humanidades, Universidad Nacional de Córdoba, Argentina. E-mail: malena.previtali@gmail.com

\begin{abstract}
Resumen
En el presente trabajo me propongo analizar los modos en que jóvenes de Villa El Nailon de la ciudad de Córdoba devienen genéricamente en hombres y mujeres a través de prácticas y sentidos legitimados y construidos socialmente en dicha villa. A partir de analizar las observaciones y entrevistas realizadas con chicos y chicas de entre 15 y 30 años aproximadamente, así como con sus familiares y vecinos es que construyo etnográficamente los sentidos y prácticas a través de las cuales se delimitan espacios y modos de habitarlos considerados favorables o desfavorables para las subjetividades que los chicos y chicas van forjando. Así, analizo la suerte de continuidad que se presenta entre los modos con que desde la más temprana infancia estructuran los usos de los distintos espacios de la villa con las divisiones y desigualdades en las relaciones de pareja. El análisis de prácticas laborales y de amistad se constituyen también en ámbitos centrales para comprender cómo el uso de la violencia en los intercambios entre jóvenes y grupos regulan las relaciones y se constituyen en espacios simbólicos para construir y demostrar masculinidades o feminidades que se enfrentan y no se doblegan fácilmente.
\end{abstract}

Palabras clave: jóvenes; espacios; parejas; género; violencia.

The girls in the house, the boys on the street. General construction, violence and sociability practices in Villa el Nylon, Córdoba.

\begin{abstract}
In the present work I propose the analyse of the ways in that youngs of Villa El Nailon of the city of Córdoba become by gender in men and women through practices and senses legitimated and built socially in said villa. From analysing the observations and interviews realized with boys and girls of between 15 and 30 years roughly, like this as with their familiar and neighbouring is that I build an ethnography of the senses and practices through which they delimit spaces and ways of inhabit them, considered favourable or desfavorables for the subjetivity that forge themselves. This way, I analyze the continuity that one presents between the manners with which from the earliest infancy they structure the uses of the different spaces of the villa with the divisions and inequalities in the relations of conyugality. The analysis of labor practices and of friendship are constituted also in central areas to understand how the use of the violence in the exchanges between young people and groups regulate the relations and are constituted in symbolic spaces to construct and to demonstrate masculinities or femininity that face and are not bent easily.
\end{abstract}

Keywords: young; spaces; couples; gender; violence.

En el presente artículo analizaré los sentidos y prácticas a partir de los cuales los chicos y las chicas de Villa El Nailon ${ }^{1}$ devienen hombres y mujeres como modos legitimados socialmente de construir subjetividades. A partir de indagar en las prácticas y discursos a través de las cuales los chicos y las chicas se van construyendo como tales, es que buscaré comprender qué sentidos hegemónicos se construyen respecto a ser varón y ser mujer en una villa de la ciudad de Córdoba. Para comprender cómo los chicos y chicas de Villa El Nailon devienen hombres y mujeres genéricamente diferenciados trabajaré este proceso a través de ciertas prácticas que aparecen estructurando sus vidas de modo significativo. Para ello

\footnotetext{
1 Los nombres de mis interlocutores han sido modificados a fin de conservar el anonimato y la privacidad de las personas involucradas.
}

me centro principalmente en registros de observaciones y entrevistas realizadas con grupos de hermanos/as y grupos de amigos/as con quienes realicé trabajo de campo entre los años 2005 y $2009^{2}$.

Analizaré aquellas experiencias diferenciales que chicos y chicas viven con respecto a los modos de ocupar, transitar y usar los espacios de la casa y la calle, y así

\footnotetext{
2 Dicho trabajo de campo fue realizado para la tesis de maestría en Antropología (UNC) "Andar en la calle y recatarse. Una etnografía sobre jóvenes, familias y violencias en Villa El Nailon-Córdoba", bajo la dirección de Ludmila da Silva Catela; así como para el doctorado en Ciencias Sociales (UBA) "Parentesco, sociabilidad y amistad en jóvenes de villa El Nailon - Córdoba. Formas y vivencias diferenciales de la violencia y el delito.", bajo la dirección de Ludmila da Silva Catela y la codirección de Daniel Míguez.
} 
comprender cómo la construcción de parejas que realizan estos chicos y chicas se presenta de manera relativamente continuada con los modos en que se administran los permisos y prohibiciones para los usos de estos espacios en la infancia y la juventud. Describiré cómo estos chicos y chicas construyen distintas formas de masculinidad y de feminidad a través de prácticas que en Villa El Nailon se presentan como significativos caminos a seguir en las trayectorias de vida: el laburo en el carro y las andadas en la calle .

Voy a contemplar por un lado aquellos reguladores de las relaciones entre jóvenes que tienen que ver con las prácticas de seducción, la formación de parejas y la construcción genérica de los usos de los espacios a través de las mismas, para luego trabajar sobre aquellas prácticas que tienen que ver con distintas formas de organizar la subsistencia y estructurar las relaciones entre amigos, vecinos, primos - generalmente del mismo sexo - en ámbitos públicos o semi públicos .

Hay distintos modos a través de los cuales los chicos de Villa El Nailon pueden construirse genéricamente en una masculinidad o en una feminidad que les puede permitir posicionarse con mayor o menor prestigio dentro de la red de relaciones de la villa. Las prácticas a través de las cuales se produce esta generización ${ }^{5}$ se enmarcan dentro de un conjunto de sentidos que se muestran fuertemente enlazados a las construcciones hegemónicas de la diferenciación genérica, donde se observa que ésta funciona como un regulador de la forma en que deben ser mirados los cuerpos, cómo serán categorizados y qué performance se tenderá siempre a realizar para responder a estos patrones y ser así clasificado dentro de un, más o menos claro, parámetro de 'normalidad' (Butler, 2001).

Para el análisis tomaré nociones sobre género que posibilitan mirar estas prácticas sociales desde desarrollos teóricos que cuestionan los usos sustancializadores del término 'género' y que posibilitan comenzar a mirar los procesos sociales tomando el género como una herramienta de análisis, que permite mostrar cómo se hace género desde modelos discursivos hegemónicos y se construyen categorías sociales sobre las que se forjan los cuerpos y los sujetos sociales. Estos modos discursivos de construirse genéricamente están anclados en las prácticas sociales e interacciones entre hombres y

\footnotetext{
3 Las cursivas serán utilizadas para referir a expresiones textuales de mis informantes, mientras que las comillas dobles referirán a citas teóricas. Las comillas simples se utilizarán para relativizar o resaltar expresiones y metáforas propias.

4 Dichas divisiones entre espacios públicos o privados serán complejizadas más adelante a la luz del análisis de los datos y de los referentes teóricos utilizados a tal fin.

${ }^{5}$ Para entender este proceso tomo la noción de género (Butler, 2002), no como aquello que se encuentra en la naturaleza y en las cosas, sino como un instrumento para significar el poder; constituye una categoría analítica a través de la cual los humanos piensan y organizan su vida social.
}

mujeres que se desarrollan en los vínculos familiares en Villa El Nailon, como vínculos fuertemente significativos en la conformación y regulación hasta el presente de las relaciones sociales en dicha comunidad. A su vez, serán analizadas aquellas performances e interacciones donde se apela fuertemente a distintas formas de violencia, para comprender qué hacen los jóvenes a través de ellas, qué tipo de vínculos, jerarquías, códigos, y principalmente formas de ser, de auto reconocerse y ser reconocidos, se producen a través de las mismas. En una palabra, qué lugar ocupan las mismas en la estructura social de las relaciones de afinidad y familiares.

Villa El Nailon es una villa de emergencia de la ciudad de Córdoba, que se encuentra ubicada en la intersección de tres barrios tradicionales de la ciudad. Constituida desde la década de 1950 por sus primeros pobladores, éstos fueron ampliando la numerosidad de los grupos familiares a partir del intercambio y el entrecruzamiento parental entre los primeros en llegar al lugar. Asentando sus viviendas a orillas de las vías del ferrocarril, los primeros habitantes - representados a través de los Villega - se constituyeron en importantes agentes mediadores con políticos locales de turno, así como con distintos actores sociales que poseían capital social y económico para conseguir $^{6}$ materiales para las viviendas, gestionar nuevos terrenos a ser ocupados, lograr que no los retiraran de los mismos, etc. Estas relaciones fueron otorgando a estos primeros pobladores de un importante reconocimiento social en la villa, conformando a estas primeras familias con fuerte poder en las relaciones vecinales e inter-barriales e invistiendo a sus integrantes de cierto reconocimiento y prestigio social en la comunidad. A partir de observaciones, charlas y entrevistas con chicos y chicas, descendientes en tercera generación ${ }^{7}$ de aquellos primeros pobladores, trabajaré cómo se produce el proceso por el que estos chicos devienen subjetivamente mujeres y varones a través de las relaciones de amistad y seducción, así como en las relaciones de pareja 'estables', donde se juegan prestigios y estatus heredados por la posición en la estructura familiar.

\section{De las relaciones de amistad y seducción...}

Las chicas que no quieran ver perjudicado el honor y prestigio de sí mismas y el de sus familias, deberán permanecer más tiempo dentro de su hogar o en las proximidades del

\footnotetext{
${ }^{6}$ La acción de conseguir aparece de manera significativa en el reconocimiento de quienes son considerados líderes comunitarios en las transacciones políticas con agentes gubernamentales o actores sociales con poder y capital para bajar materiales, dinero, planes asistenciales, subsidios, alimentos, juguetes, etc. que se constituyen en elementos fundamentales para muchas familias de Villa El Nailon. Así, es utilizada de manera autoreferencial a través del yo consigo... o bien para señalar a otro como él siempre consigue...

${ }^{7}$ La tercera generación es considerada de esta manera por los mismos habitantes de la villa para referirse a aquellos jóvenes que comprenden entre los 15 y los 25 años aproximadamente y que son los nietos de aquellos primeros habitantes que asentaron sus viviendas a las orillas de las vías del ferrocarril hace más de 50 años.
} 
mismo, que el tiempo que destinen a andar en la calle y estar ahí charlando con los chicos. De este modo estarían respetando ciertos parámetros sostenidos en la villa sobre qué es ser una chica de su casa o bien una chica que siempre anda en la calle. Si bien estas son las normativas que implícitamente, y a veces explícitamente, rigen y buscan ordenar los comportamientos de los chicos y chicas, éstos últimos van acomodándose a las mismas, modificándolas, burlándolas y/o amortiguando las acusaciones y juicios que sobre ellos recaen. Esto lo logran a través de diversas estrategias que implican distintos modos de sociabilidad dentro y fuera del espacio de la villa. Las prácticas de sociabilidad que las chicas realizan se pueden clasificar según el grado de proximidad o distanciamiento respecto a aquellos parámetros establecidos desde el 'mundo adulto familiar' respecto a lo que garantiza constituirse en una chica de la casa o una que siempre anda, como espacios moralmente distanciados y significativos en la determinación de las posiciones que las distintas familias van ocupando en la red social de la villa. Si bien hay chicas que no se encuadran necesariamente en una sola de estas modalidades de usar y andar por los espacios de la villa, la descripción que sigue sirve a los términos de mostrar distintas opciones y así distintas prácticas recurrentes que he registrado durante el trabajo de campo.

Por un lado se encuentran aquellas chicas que tienen fuerte interés por andar en la calle y frecuentar los bailes el fin de semana, más allá de cómo esto pueda afectar a la reputación de su familia, ya que se sienten motivadas a compartir encuentros y miradas con chicos con los que pueden entablar vínculos de noviazgo o de amistad. Aquellas chicas sobre las que recaen prohibiciones impuestas desde los adultos de la familia para circular tanto por la Mendoza ${ }^{8}$ como por zonas alejadas de la villa verán restringidas sus posibilidades de transitar por estas zonas según el nivel de rigidez y control que los padres y adultos logren imponerles. Algunas chicas se empapan ellas mismas de ciertos criterios de diferenciación de las zonas de la villa 'que no son buenas de frecuentar' y deciden por sí mismas construir vínculos con quienes comparten ese criterio: con primas que vivan en las proximidades de su casa, con compañeras de la escuela, con sus hermanas y sobrinos/as, etc. La Mendoza se constituye en uno de los sectores sobre los que recaen las mayores sospechas y cuestionamientos respecto a qué acciones e intercambios realizan o planifican allí los jóvenes. Esto es promovido así por quienes juzgan de manera negativa el que los jóvenes se reúnan allí a hacer nada ${ }^{9}$. Es por

\footnotetext{
${ }^{8}$ La Mendoza es la calle que atraviesa la villa y la divide en dos sectores así reconocidos por sus habitantes. Hacia uno de los costados de esta calle se halla la primera cancha de fútbol del lugar, donde se juegan partidos y campeonatos. A su vez, en las casas frente a esta cancha suelen reunirse grupos de chicos y chicas, ya sea para observar los partidos o tan sólo para reunirse allí, lo que la hace a La Mendoza un lugar sumamente atractivo para circular y encontrarse.

9 Este hacer nada implica variadas formas de intercambio y de presentación de sí ante los otros. Aquellas actividades que mayores sospechas suscitan para algunos adultos son aquellas en que los jóvenes
}

ello que difícilmente pueda ser aprobado a los ojos de la opinión pública de la comunidad que aquellas chicas que rondan entre los 12 y 19 años aproximadamente y que aún dependen del resguardo de sus familias anden por la calle, que en este caso es prácticamente sinónimo de andar por la Mendoza.

Por otro lado, es posible encontrar chicas que viven en alguna de las casas que se encuentran justo sobre calle Mendoza. Esto las ubica en un constante acceso al espacio de mayor circulación e interacción de chicos y chicas, sin por ello poner en riesgo su reputación, ya que estarían simplemente en la puerta de su casa al mismo tiempo que participarían de los intercambios con chicos y chicas que esta ubicación estratégica les brindaría. Por último, están aquellas chicas que pueden ocupar espacios y generar encuentros e intercambios tanto cerca de sus viviendas como lejos de las mismas, sin que esto genere una mayor preocupación por parte de sus familias. Los juicios que pueden recaer sobre éstas varían a su vez en relación a las rivalidades que existen entre las familias, así como a las diversas disputas personales que pueden suscitarse entre los miembros de algunas de ellas. Sin embargo, si bien estas dinámicas rigen en mayor o menor medida las posibilidades de encuentros y circulación por los espacios de la villa entre chicos y chicas, éstos pueden a su vez escapar a algunas de estas miradas acusatorias y crear lógicas propias de intercambio y seducción con los chicos que ocupen su interés.

Resultó interesante observar que muchas veces no es tanto la frecuencia con que las chicas habiten estos espacios lo que las ubicará como una chica de su casa o una chica que anda con la junta; sino que serán las prácticas que en ellos realice y los modos en que se lleve a cabo. Una chica no será objeto de acusaciones si circula alejada de su casa bajo la justificación de cumplir con el pedido que le hiciera su madre de enviar un mensaje a un familiar o vecino, de ir al almacén a realizar una compra, ir a buscar un hermano o hermana a la casa de otra persona, a la escuela, o actividades que tengan alguna vinculación con los intercambios familiares ${ }^{10}$. Cuando no median estos asuntos familiares y las chicas están allí charlando con amigos, primos y vecinos, mirando un partido de fútbol o jugando a los videitos, será factible escuchar, por parte de quienes se alejan en la trama parental de éstas, opiniones cargadas de valoraciones morales sobre las conductas de estas chicas así como sobre las estrategias educativas de sus padres.

discuten enfrentamientos con otros grupos, muestran las armas que poseen, planifican robos y discuten sobre posibles enfrentamientos con la policía.

10 Fonseca (2000) plantea, para el contexto brasilero, que entre las distintas estrategias que las mujeres pueden darse para circular por los distintos espacios de la villa figuran con preponderancia la el tener que resolver asuntos familiares como principal 'excusa' para no poner en juego el "honor familiar" construido, ni reputaciones personales dentro de las familias. 
En Mayo de 2005 las chicas que ahora tienen 18 años, tenían en aquel entonces 13 años y disfrutaban de las relaciones pasajeras de noviazgo que sostenían con chicos de su edad o más chicos. Caminando con tres de ellas por calle Mendoza y sus alrededores notamos que a los costados de ésta, sentados en el piso, estaban los chicos de barrio Hipólito ${ }^{11}$ allí reunidos. Esto inhibió a Lara ${ }^{12}$ y a Luciana ${ }^{13}$ de pasar por donde estaban ellos, pero no lo hizo con Betiana ${ }^{14}$, quien vive en una de las casas que da a calle Mendoza. Caminando por allí con ella me cuenta que tranzó ${ }^{15}$ con uno de ellos, y esto era motivo más que suficiente para que su cuerpo se inhibiera y pasara delante de ellos caminando rápido, con la cabeza mirando hacia abajo. Uno de ellos comenta: ahí pasa tu mujer Paco. Una vez que dejamos atrás ese tramo de La Mendoza, Betiana se relaja y al volver a encontrarse con sus dos amigas, les comenta sorprendida lo sucedido.

Caminar libremente por calle Mendoza y por los pasillos que se desprenden de la misma se constituye en toda una hazaña para chicas como Lara y Luciana que, al no vivir sobre esta calle, deben encontrar generalmente motivos que justifiquen su circulación por esta zona, a menos que dejen poner en evidencia su interés por encontrarse allí con los chicos de Hipólito. Mientras vamos caminando hacia otro sector de la villa, ellas me van relatando que suelen juntarse con los chicos en el pool que funciona en una casa de calle Mendoza. Durante la tarde se acercan chicos de entre 10 y 16 años y más tarde llegan los más grandes. Los chicos pagan las fichas para los videitos y otras veces son ellas las que compran fichas para todos. Se juntan todos ahí y fuman porros ${ }^{16}$, explica Betiana, aclarando que ellas se mantienen alejadas de esas prácticas.

Por su parte, los chicos de la villa y aquellos que vienen de barrios cercanos a la misma, circulan por distintos espacios y sectores de ésta según con quiénes se encuentren y qué actividad van a hacer allí (jugar al fútbol, juntarse a fumar, hacer nada, etc.). Es por ello que para las chicas tampoco tiene el mismo valor recorrer un pasillo $u$

\footnotetext{
11 Barrio colindante a villa El Nailon hacia el noreste de la misma.

12 Lara y sus hermanos forman parte de la tercera generación en descendencia de los Villega, siendo su padre uno de los principales líderes comunitarios que tuvo la villa en los últimos años. Esto, sumado al ascenso económico de su familia, le vale a Lara un estatus mayor en relación a otras chicas de la villa.

13 Luciana tenía 14 años en ese momento y si bien su padre se mostró siempre en oposición a que su hija frecuente los bailes los fines de semana, no sucedía lo mismo con las posibilidades para ella de circular por barrios cercanos a la villa o en algunas zonas dentro de la misma. Luciana es nieta de Lidia, una de las primeras pobladoras del lugar que no pertenecía a la rama de los Villega pero que ha ganado importante reconocimiento en la comunidad.

14 Betiana es hija de una mujer que llegó hace 15 años a la villa al juntarse con uno de los descendientes de los Villega. Betiana dejó la escuela al comenzar el nivel medio y desde entonces cuando le pregunto qué hace durante el día me contesta: nada, estoy en mi casa.

15 Tranzar: besarse.

16 Porro: cigarrillos de marihuana.
}

otro, una calle u otra. Betiana reconocía que le interesa recorrer más aquellos pasillos donde sabe que los chicos de Hipólito permanecen más tiempo, porque se quedan en la casa de algún familiar o amigo. Las chicas que no viven en la villa se reúnen en lugares estratégicos de esta para tener más oportunidades de cruzar allí a los chicos. Si bien el interés que manifiestan tanto unos como otros por participar de aquel juego de encuentros sin miradas o miradas sin encuentros puede ser fuerte motivador para reunirse y andar, este no es el único motivo que los convoca, aunque por momentos puede ser uno de los más importantes.

Los grupos de varones que poseen entre 15 y 24 años se reúnen en la puerta de la casa de uno de ellos, en sitios donde encuentran unos ladrillos o algún tronco donde sentarse, o bien en las mismas vías del tren. Los he visto sentados o agachados, unos sobre un riel y otros sobre el otro, favoreciendo la interacción cara a cara o bien todos sobre el mismo riel mirando hacia la canchita para ver quien pasa y quien juega al fútbol. Comparten una coca, fuman marihuana, comentan sobre incidentes protagonizados por alguno de ellos el fin de semana, se hacen chistes y se ríen al respecto; hablan de fútbol, sobre negocios ${ }^{17}$ por hacer, sobre otros temas, o simplemente están allí, haciendo nada. Estos lugares de reunión de los chicos, si bien forman parte del 'afuera' de las casas, y presentan características claramente diferenciales con respecto al 'adentro' de éstas, no se presentan con el anonimato con que suelen ser caracterizados los espacios públicos (Magnani, 1992, citado por Spósito, 1994). El alto grado de apropiación simbólica que los chicos manifiestan respecto a los mismos es en gran medida lo que permite que adquieran esta cualidad de lugares intermedios entre la casa y los espacios públicos. Magnani analiza espacios que se presentan como intermedios entre lo público y lo privado, donde los jóvenes desarrollan una sociabilidad más amplia que aquella que encuentran en los vínculos familiares. Así, cuestiona las oposiciones clasificatorias que se reifican socialmente y no permiten ver que son términos relacionales, como por ejemplo público-privado, casa-calle, etc. (Magnani, 2005: 178)

Si bien en estos modos de reunirse y hacer nada parecen no necesitar de mucho diálogo entre ellos y es la forma que los chicos tienen de nombrar aquello que hacen, en términos antropológicos están haciendo mucho más que nada. Los chicos están construyendo un espacio de encuentro, un espacio de pertenencia, de afianciamiento de los vínculos entre ellos. Están adquiriendo experiencia en la calle, mostrándose como quienes tienen calle ${ }^{18}$, y en

\footnotetext{
17 Negocios le llaman a la venta de objetos que circulan en circuitos ilegales.

18 Tener calle hace referencia a la acumulación de experiencias que implican un relativamente amplio conocimiento de distintas zonas y personas del lugar, así como de otros barrios. Si estas experiencias están referidas a haber atravesado situaciones de violencia física y enfrentamientos con armas con otros jóvenes, o haber participado en diversos robos, se acrecienta aún más el tener calle y con ello el prestigio
} 
este mismo proceso, construyendo alianzas que pueden ser cruciales para la vida en la villa ${ }^{19}$.

Cuando los chicos se reúnen en los puntos de encuentro más frecuentes, conciertan negocios con sus amigos de barrios vecinos ${ }^{20}$, afianzan sus vínculos de amistad o bien definen por dónde y entre quiénes se disputan las rivalidades. Así reinstauran jerarquías entre quienes conforman los grupos y al mismo tiempo, y a través de todos esos elementos, se constituyen como potenciales embrollos ${ }^{21}$ para las chicas.

Daniel acababa de recuperarse de la bala que había disparado en su abdomen un hombre al que le había robado la bicicleta. Por otro lado, Manuel había salido hacía poco de un instituto de menores en el que había estado internado varios meses. Junto con Talo ${ }^{22}$ y otros chicos, disfrutaban todos del último sol de la tarde que daba justo contra la pared del kiosco donde estaban apoyados. Talo se pone a comer un sándwich que alguien le alcanzó desde el kiosco. Daniel estaba parado contra la pared y fumaba un cigarrillo, mostrando importantes aires de grandeza. Me acerco y los saludo. Ellos me responden. Daniel lo hace con el mismo aire altanero con el que se llevaba el cigarrillo a la boca. Charlando con Talo no noté cómo fue que la conversación entre Daniel y Manuel desencadenó en un intercambio de palabras que en pocos segundos comenzó a tornarse en una pelea verbal.

Daniel: isi sos un gil vo!

Manuel: ipero a mi no me pegaron un tiro...!

Y así continuaron provocándose, en un diálogo en es-

$\overline{\text { que este joven pueda ostentar en las relaciones sociales donde esto se }}$ constituye en un valor. Esto es trabajado en mayor profundidad en la tesis de maestría antes nombrada.

19 En este sentido, los estudios culturalistas de la escuela de Birmimghan han brindado interesantes aportes para pensar en aquellas acciones de los jóvenes que, a pesar de haber sido consideradas en numerosos estudios sólo como momentos de transición o de suspensión entre actividades que sí adquirirían cierto de grado de significación teórica, éstos desarrollan sus actividades cotidianas a través del paso del tiempo y del acompañarse en ese 'hacer nada', que para Corrigan (1976) condensa una serie de sucesos que están cargados de los modos en que estos jóvenes "construyen subculturas complejas" (Corrigan, 1976).

20 Esto permite desnaturalizar aquellas representaciones que excluyen a los jóvenes que viven en barrios de clase media como partícipes de actividades delictivas, mientras que centra la exclusividad de dichas prácticas en aquellos jóvenes que viven e las villas de la ciudad. Barrios como Marques de Sobremonte e Hipólito Irigoyen presentan una diversidad significativa en la población que allí habita, por lo que sería pertinente enfocar el interés de estudio hacia esas complejas configuraciones barriales de la ciudad.

21 Modo en que chicos y chicas se refieren al encuentro físico, amoroso y pasajero que sucede entre ellos.

22 Talo y Manuel son hermanos y tienen actualmente 18 y 19 años respectivamente. Ambos son descendientes de los Villega y, así como varios de sus primos y medios-hermanos, han forjado su prestigio entre los varones y su poder de seducción para con las chicas no sólo a partir de sus cuerpos altos y delgados, sino también a partir de la fama adquirida de saber moverse en la calle y en el robo. calada hacia tonos y posturas que expresaban cada vez mayor enojo. Aquí se puede observar cómo a partir de categorías de clasificación, como la de gil, configuradas a través de las experiencias de los chicos en el choreo ${ }^{23}$, de sus tránsitos por los institutos, de las andadas en la calle, etc. éstos van negociando posiciones de poder, construyendo amigos o amistades. A lo largo de su vida Manuel ha ido diferenciando quiénes son para él los amigos y quiénes son las amistades. Con los primeros entiende por tales a aquellas personas con quienes puede compartir una diversidad de espacios y situaciones. Es decir, amigos son quienes perduran y comparten las penas y las alegrías, mientras que las amistades serían aquellos chicos con quienes sólo se comparten las salidas a robar, los negocios a concertar, etc.

\section{...a la vida en pareja}

En charlas y encuentros con los chicos y chicas de la villa emergían sus concepciones respecto a los lugares físicos y simbólicos otorgados a mujeres y hombres en las relaciones cotidianas y no cotidianas. En los comienzos del trabajo de campo, cuando me acercaba a los grupos percibía la extrañeza que a ellos les provocaba mi presencia allí, cuestionándola de la siguiente manera: ¿qué hace acá que no está lavando la ropa en su casa?, o bien ¿no tiene casa usted que se queda hasta esta hora acá? Si bien había en estas preguntas una intensión de amenizar con bromas la situación, no por ello dejaban de reflejar aquellas concepciones con roles claramente diferenciados entre varones y mujeres, donde estas últimas deben permanecer en mayor medida que los hombres dentro de la casa, deben ocuparse de la limpieza de ésta y de la ropa de los integrantes de la familia, deben cocinar para todos ellos y estar al tanto de lo que hacen los hijos/as ${ }^{24}$; mientras los hombres serán quienes estarán reunidos largas horas en la puerta de la casa de alguno de ellos, en la canchita de fútbol, o bien podrán ir al baile o a bares del centro con sus hermanos y amigos y no tener horarios ni tareas fijas que realizar durante los fines de semana.

Lo trabajado por Bourdieu (1968) en la sociedad de Cabilia muestra cómo las oposiciones construidas en torno a lo masculino como lo protector, la fuerza, el prestigio, y lo femenino como lo impuro, culpable, vergonzoso, secreto y sagrado, también se expresan en la división de espacios que estos ocupan en la comunidad. Salvando

\footnotetext{
23 Chorear proviene del lunfardo porteño que habla del chorro como de la persona que realiza la acción de robar. En el contexto de esta villa y en el entorno regional se utiliza choro, y chorear como la acción.

24 En trabajos realizados (Gutiérrez, 2002; Rodigou, 2002; Rotondi, 2000) en distintos barrios de la ciudad de Córdoba se encontraron que las parejas se estructuran en base a divisiones en roles sexuales que responden al siguiente modelo: el hombre trabaja afuera y la mujer trabaja en la casa en actividades no reconocidas como 'trabajo'. Sin embargo, estas autoras resaltan progresivos cambios que se ha ido produciendo en estas divisiones, los cuales se viven con más o menos conflictos y dificultades según los distintos sectores sociales.
} 
las distancias, esa vergüenza y cuestionamiento al honor que los hombres y mujeres pueden vivir en Cabilia en caso de no respetar estas divisiones, se observa en las distintas formas de habitar y ocupar los espacios que se van transmitiendo para los chicos y chicas de Villa El Nailon. Sin embargo, los chicos y chicas de la villa desarrollan distintas estrategias para escapar de algún modo a la sanción que pudiera provenir de la opinión pública por habitar y usar los espacios de modos disruptivos a las expectativas comunitarias al respecto.

Lorena, hermana de Caro $^{25}$, quien no ha entablado una relación estable con un hombre como ha hecho su hermana, ha construido sus representaciones $y$ prácticas sobre las relaciones entre hombres y mujeres a través de una trayectoria fuertemente signada por una alta ponderación de las relaciones de amistad que ha sostenido con gran cantidad de chicos de la villa y barrios cercanos. Lorena se presenta como quien experimenta a lo largo de su vida la libertad de hacer siempre lo que quiere.

Estábamos charlando con Lorena y Esther en la casa de ellas. Lorena reafirma: a mi nadie me manda, nadie me dice qué tengo que hacer.... Esto venía a colación de sus relaciones pasadas con hombres y a su relación con la madre de uno de ellos, con quien hay fuertes tensiones y acusaciones. Así, ella relata cómo las parejas que han estado con ella han debido saber aceptar que ella tiene más amigos varones que mujeres, tal como ella lo explicita.

Lorena: ¿te acordás Malena cuando fuimos al baile de la Mona con todos los chicos? Estaba el Chelo, el Papio... y cayó el Pablito (quien era su novio en ese entonces), que me había dicho que no iba a ir... uh! ¿Te acordás? ¡Era más celoso ese!

Esther: jEl Alberto era re absorbente, re absorbente! jno me dejaba arreglarme y si me veía charlando con un amigo se enojaba!

Estas experiencias y percepciones van conformando para cada una de las trayectorias de chicas y chicos de la villa modos particulares de significar los vínculos parentales, los vínculos de amistad y de pareja. A través de las vivencias en sus relaciones de pareja construyen sus representaciones y prácticas en torno a lo permitido, lo prohibido, lo esperable y lo no esperable en las mismas, contribuyendo esto a ciertos modos de estructurar y resolver los conflictos que vivencian en las dinámicas familiares.

\footnotetext{
25 Lorena y Caro se reconocen como hermanas debido a que "se criaron juntas". La ponderación de los vínculos entre quienes "se criaron juntos" se significa de igual manera que aquellos casos de hermanos que comparten padre y madre. En el caso de Lorena y Caro esto se da así debido a que Caro se crió durante algunos años de su infancia con la madre de Lorena, Esther, y también significa dicho vínculo como de madre-hija.
}

Al visitar distintas familias encontraba que las mujeres estaban generalmente lavando la ropa, barriendo el piso de la casa y del patio, lavando los platos, cocinando, o bien tomando mate y charlando entre hermanas, vecinas, primas y amigas. Voy a buscar a Mariela ${ }^{26}$ a la casa de su hermana, donde estaba viviendo hacía unos meses. Iríamos al baile de la Mona Jiménez ${ }^{27}$. Para ello, una de las hermanas de Mariela se quedaría cuidando a su hija de un año. En la mesa de la sala principal de la casa estaban las dos hermanas de Mariela y un amigo de ellas jugando a las cartas. Mientras Mariela termina de arreglarse yo me siento a charlar con ellos. Me preguntan qué hacía esa noche mi novio, ya que al parecer les intrigaba la situación de que yo saliera sin él. Me preguntan si acaso él me deja salir sola. Yo les explicaba que sí, que no es que él me tenga que dar permiso, sino que yo puedo salir sola si así lo quiero. A ellas les parecía sumamente extraño esto y les provocaba risa; a lo cual agregan el siguiente comentario: para mi que la Malena se le piró al novio... ${ }^{28}$

Esto muestra cómo en la lógica de regulación de las parejas, para ellas las posibilidades de que las mujeres continúen yendo al baile y saliendo con amigas sin sus maridos $^{29}$ es posible sólo negociando esto con muchos días de antelación, preparando a éste para aceptar la idea, consiguiendo quien pueda y quiera ocuparse de sus hijos durante esa noche, y pirándose. Tanto hombres como mujeres contribuyen para el sostenimiento de esta distribución de las posibilidades de salir o no con amigos/ as, al baile, al centro, etc.

Mariela y sus dos hermanas mayores tienen entre $20 \mathrm{y}$ 27 años. Las tres ya tienen hijos y viven con sus parejas. Años atrás ellas compartían grupos de amigos con los que no sólo salían los fines de semana, sino que también compartían largas noches de juntadas durante la semana. Fue en estas salidas donde conocieron a los padres de sus primeros hijos, con quienes no sostuvieron una relación. Las tres hermanas se muestran por momentos convencidas que así es el modo en que deben organizarse las actividades sociales en una pareja con hijos a cargo, y en otras circunstancias manifiestan claramente cierta nostalgia por los momentos pasados, el lamento de hallarse 'imposibilitadas' a repetirlos y a veces disgustadas

\footnotetext{
${ }^{26}$ Tami, Mariela y Caro son parte de las primeras descendientes en tercera generación de los Villega. Lorena, de quien hablaré más adelante, se ubicaría en la misma línea familiar que ellas porque "se criaron juntas" aunque no sea hija biológica del mismo padre ni de la misma madre. Este tipo de lazo social se hace crucial en la villa debido a la alta rotación de miembros de las distintas familias así como al alto nivel de convivencia entre niños/as y jóvenes de familias emparentadas.

27 como el máximo exponente de este estilo musical.

28 La expresión "se piró" se utiliza para referirse a que alguien se escapó.

29 Los miembros de las parejas ya estabilizadas en el tiempo se reconocen entre sí y en el resto de la comunidad como "el marido de..." y "la mujer de..." aunque no hayan contraído matrimonio ante el registro civil ni ante la iglesia.
} 
con sus actuales parejas por la restricción que viven en este desigual modo de administrar las salidas con amigos/ as.

Tami, la mayor de las tres hermanas, me comenta que ella irá el viernes al baile de Ulises Bueno ${ }^{30}$ con sus cuñadas, suegra y amigas de éstas porque festejarían el cumpleaños de una de ellas. Su marido ya había manifestado su oposición a esto. Sin embargo, ella se mostraba firme ante la idea de lograr que ese fin de semana él no salga y se quede con los hijos de ambos. Estábamos hablando de esto cuando pasa él y comenta que no dejará que ella salga el fin de semana, a lo que ella responde: iya te dije yo que yo voy a salir, me toca a mi ahora! Tami puede negociar estos asuntos ya que encuentra un mayor marco de legitimidad para sus salidas al realizarlas junto con el grupo de mujeres pertenecientes a la familia de su marido ${ }^{31}$, para quienes estas salidas de fines de semana son consideradas parte habitual de la vida de sus integrantes, así sean mujeres o varones. Esta estructuración intergenérica debe ser comprendida en el marco más general de las relaciones familiares que exceden al mero vínculo de las dos personas que conforman la pareja marital. Así como se observaba que en la familia del marido de Tami las actividades de esparcimiento entre las mujeres pueden ser algo habitual, aunque éstas tengan hijos y una familia 'a su cargo'; por el lado de la familia de origen de Mariela y Tami estas actividades para las mujeres no se significan de la misma manera. La madre de estas tres hermanas y su actual marido se ocupan especialmente del cuidado de la hija de Mariela desde que ésta nació. Ellos se muestran sumamente molestos ante el interés de Mariela de salir con amigas al baile. Así expresan su preocupación: jella ya tiene una hija. Si la chica se levanta mal ella ni se entera! Nosotros le avisamos por mensajito pero ella ni viene. Nosotros no tenemos problema de quedarnos con ella si es para que ella se vaya a trabajar, pero no para que se vaya al baile.

Las trayectorias que estas chicas recorren en el marco de las relaciones familiares significativas que ellas viven en Villa El Nailon van determinando en gran medida cómo éstas experimentan otras relaciones, como las de amistad y las interacciones en el baile, que a su vez pueden verse modificadas en relación al tener o no tener hijos y a la conformación de una pareja estable. Estas concepciones, prohibiciones, restricciones y permisos que organizan las actividades y espacios que chicos y

\footnotetext{
30 Ulises Bueno es un cuartetero cordobés que adquirió popularidad en el último año, la cual vino fuertemente de la mano de ser el hermano menor del fallecido Rodrigo Bueno, quien fuera hace 9 años atrás uno de los cuarteteros más populares en la provincia de Córdoba, con la característica de haber logrado captar la atención del público porteño.

31 Este grupo de mujeres con quienes Tami se une por lazos de parentesco político viven en uno de los barrios vecinos a Villa El Nailon, por lo que generalmente las reuniones y salidas las organizan en casa de su suegra y no en la villa, donde vive Tami.
}

chicas, hombres y mujeres realizan en su vida familiar, estructuran las maneras 'correctas' y las 'incorrectas' de moverse dentro de ellas. También es posible observar que, siguiendo distintas trayectorias, aparecen diversas relaciones determinando en mayor medida que otras los recorridos, prácticas y representaciones que estos chicos y chicas sostienen sobre cómo deben ser las relaciones entre géneros. Los modos particulares a través de los cuales los chicos y chicas de Villa El Nailon devienen de géneros vivenciados de modos dicotómicos - hombres, mujeres - se produce a través de las distintas prácticas y relaciones que construyen su cotidianeidad: el fútbol, el trabajo en el carro, los bailes de cuarteto, las andadas por fuera y dentro de la villa, los encuentros en las vías del tren, la rivalidad entre grupos, los estilos al vestirse, entre otras. Muchos trabajos toman el género, la clase, la raza, etc. como capas que van haciendo al sujeto y que van predominando por sobre lo biológico, pero no permiten ver cómo los sujetos devienen de 'un sexo', de 'un género' en la misma medida en que devienen de una clase, de una raza. Al ir haciendo género, los sujetos van construyendo todas las formas de relación social en las que se desarrollan ${ }^{32}$. A través del sostenimiento de oposiciones entre roles fijados y reafirmados en las prácticas e interacciones cotidianas, tanto unos como otros devienen a través de lógicas de subjetivación que se enmarcan en sentidos sostenidos social y comunitariamente. En un diálogo con dos jóvenes de la villa emergen sus concepciones respecto al modo en que se dirimen los conflictos con sus parejas:

Néstor ${ }^{33}$, que se había separado de su mujer semanas atrás, había vuelto con ella. Sin saber el motivo de la separación, pero sugiriendo en broma que él había estado en falta con ella, le pregunto: ¿le pediste perdón?

Néstor: perro que se va sin que lo echen vuelve sin que lo llamen...

Sebastián ${ }^{34}$ : a las mujeres no se les pide perdón...

Néstor: yo te voy a explicar como es: cuando la mujer se enoja vos vas te acercás y le das un beso, justo el punto débil... y listo.

Sebastián: che, 'punto débil', pasame el palo aquel del carro.

Si bien Néstor puede estar exagerando su percepción a través una interacción jocosa sobre el tema, no deja esto de reflejar aspectos de la percepción que los varones jóvenes construyen sobre los modos en que se dirimen los conflictos con sus parejas. Cuando una pareja ya tiene

\footnotetext{
32 En su trabajo en los bailes de cuarteto de Córdoba Blázquez (2008) encuentra cómo los jóvenes que frecuentan estos espacios no sólo se construyen genéricamente a través de la danza en hombres y mujeres relacionados de manera heterogenérica, sino que también construyen un conjunto amplio de clasificaciones y categorizaciones a través de las cuales dibujan divisiones de clases, etáreas, culturales, etc.

33 Nestor también es nieto de los primeros Villega que llegaron a la villa y por tanto es primo de las chicas presentadas anteriormente.

34 Sebastián es hermano de Tami, Caro y Mariela, por lo que es primo también de Néstor.
} 
hijos y comparten un mismo techo, cuando son marido $y$ mujer ${ }^{35}$, ambos suponen que deberán sortear todo tipo de conflicto y que el vínculo persistirá de todos modos.

Esther $^{36}$ sostiene que son las mismas mujeres las que contribuyen a que los hombres sientan que ellos son 'dueños de hacer lo que quieran'. Al referirse a la generación de hombres como su ex marido y los hermanos y primos de éste (es decir la segunda generación de los Villega), ella realiza la siguiente reflexión: ellos han aprendido desde que nacieron a que el hombre es quien pone los puntos en la casa. Si la propia madre les decía que el hombre tenía que tener a la mujer a los golpes. Esto muestra cómo la transmisión intergeneracional de qué posiciones deben ir siendo ocupadas por unos y otros en la organización de la familia y por tanto de la reproducción de la vida social en la villa, va mostrando la perduración en el tiempo de algunas relaciones marcadas por la violencia y la desigualdad, a su vez que otras muestran la posibilidad de cambios en el proceso de construcción de la propia subjetividad así como del grupo social de referencia.

Hombres y mujeres se involucran en estos modos de construir sus familias por diversos motivos. Los chicos pueden dejar la calle, las drogas, el choreo y abocarse a intentar una vida con menores riesgos y que les garantice una mínima subsistencia para sus mujeres y sus hijos. Estas son también parte de las apuestas que los varones hacen por su vida en pareja y por sus hijos, aceptando que sean sus mujeres quienes de allí en más intentan 'controlar' que éstos no retomen aquellas andadas en la noche, el alcohol y el robo. Así relata $\mathrm{Maco}^{37}$ su experiencia en relación a cómo su vida fue virando de los espacios del choreo y la cárcel a la constitución de una familia y el trabajo con el carro 38 :

Si yo de chiquito que me mando solo, yo a los siete años ya me mandaba solo. Cuando era chico, era chorito yo. Después estuve en cana. Y cuando salí de la cana me fui a la casa de una mina que era más grande que yo. Cinco años estuvimos. Ahí nació la Yanina. Me volví a la villa y ahí me junté con la Nati. Y cuando nació la Evelin

\footnotetext{
35 Las características que Jelin (2006) describe para hablar de la conformación de una familia: convivencia, sexualidad y procreación, configuran en Villa El Nailon a una pareja en familia desde el momento en que tienen hijos en común y deciden vivir juntos.

36 Mujer de 45 años, madre de seis hijos, entre ellos Lorena, Manuel y Talo, de quienes hablaré más adelante.

37 Maco es un joven de 28 años que en los últimos 10 años se dedica a trabajar con el carro realizando changas en barrios vecinos. Es uno de los nietos de aquellos primeros pobladores de la villa (los Villega), y si bien estuvo involucrado en el delito durante su adolescencia, actualmente se dedica al trabajo en el carro, a pesar de que esporádicamente incurra en el robo de objetos 'dejados al descuido'.

38 El laburo en el carro consiste en salir a hacer changas, lo que implica salir en el carro con caballos y ofrecer servicios a casas de barrios vecinos como quitar escombros, podar árboles, arreglar algún desperfecto de la casa, etc.
}

dejé todo... Primero nació la Yanina (con la otra mujer) y yo seguía choreando, después nació la Evelin y ya no choreé más, y después nació la petisa y así...

Descolá (2005) plantea, para la sociedad de los jívaros con la que él trabaja, que la división de espacios dentro de la casa, de tareas, obligaciones, derechos y privilegios para hombres y mujeres hace a la organización de la vida de ese poblado, donde unos y otros forman parte fundamental del sostenimiento de esa cultura como tal. Salvando las distancias espaciales y temporales, en villa El Nailon esta forma de apoyo y sostenimiento en dicha distribución de roles, espacios y expectativas también funciona en la base de las relaciones sociales en dicha comunidad y organiza gran parte de las interacciones.

\section{El laburo en el carro y el andar en la calle.}

Para los jóvenes que trabajan con el carro, como es el caso de Maco y sus amigos, aquellos niños que desde pequeños se incluyen en estas actividades se merecen apreciaciones como la que sigue: jeste va a ser un vivo! mirá como anda en el carro. Brian, el hijo de Caro, de siete años de edad, ha acompañado con entusiasmo las actividades de su tío Maco en el carro desde muy pequeño. Aprender a manejar los caballos, saber atarlos, llevarlos a pastar, ir a buscarlos, manejar las riendas, etc., pueden ser actividades que, desarrolladas desde la temprana infancia, orienten en gran medida la trayectoria de un chico de la villa. A su vez, los dos hermanos menores a Maco han desarrollado trayectorias ligadas más bien a una masculinidad construida en base a actividades delictivas. Estas actividades las pueden realizar con otros con quienes comparten representaciones sobre el trabajo en el carro en donde esta es vista como una actividad deshonrosa, que implica bajar de estatus y formar parte de otros espacios de sociabilidad, en el cual los factores que garantizan la construcción de masculinidades son diferentes a aquellos que se encuentran en las sociabilidades del mundo del robo.

Los distintos modos de devenir hombres y mujeres que desarrollan los jóvenes en Villa El Nailon pueden expresarse a través de sentidos construidos en torno a dos actividades centrales: salir en el carro y andar en la calle. Si bien en principio parecieran dos actividades que nuclean casi exclusivamente a varones y no a mujeres, es posible observar que a través de ciertas modalidades de asumir estas prácticas o de significarlas, las chicas también se construyen genéricamente como tales.

Maco y Sebastián, hermanos de 29 y 28 años de edad respectivamente, trabajan con el carro hace 10 años aproximadamente, y se han constituido en un modelo a seguir para su sobrino Brian. Así, los niños en la villa juegan a construir sus carros y a transportar objetos en ellos como hacen sus padres y tíos. En este ámbito de construcción subjetiva, para llegar a ganarse un reconocimiento como 
tiene Maco, los chicos deben aprender a posicionarse de manera firme en las transacciones que realizan con otros. 'Posicionarse de manera firme' implica en muchos casos recurrir a ciertas formas de violencia que garantizan no ceder en 'lo ganado', sea material o simbólico.

Maco cuenta cuáles son los costos en dinero para tener carros y caballos: un carro le cuesta unos $\$ 300$ y el caballo - dependiendo de ciertas condiciones - puede costarle alrededor de $\$ 600^{39}$. Pero para Maco no todo se gana con dinero. Así me relata cómo obtuvo el carro que estaba arreglando: ... este me lo dieron... porque me habian choreado un caballo y entonces para que no lo hiciera cagar $^{40}$ me dio el carro. Negociando con un hombre que vive en un barrio vecino a la villa, sostiene el siguiente diálogo:

\section{Maco: ¿pero qué querés exactamente?}

Hombre: un hierro de cuatro metros.

Maco: yo te lo consigo, pero más tarde, a la noche.

Hombre: ¿de dónde vas a sacar?

Maco: y...por ahí, podemos sacar...

Hombre: ahí hay mirá. (y señala hacia la Iglesia católica que está a una cuadra)

Maco: ¡no, nosotros con la Iglesia no nos metemos! No, por allá hay uno que te puedo conseguir. No te preocupes, esta noche yo te lo tengo.

Maco va construyendo su fama, su prestigio, sabiendo negociar en las circunstancias adecuadas y respetando códigos instaurados implícita y explícitamente. Esto es, aclarando que él puede arreglar un negocio pero respetando ciertas reglas: con la Iglesia no se mete. Maco ha ganado respeto y reconocimiento en el marco de sus relaciones familiares así como con quienes concreta trabajos y negocios. Esto se debe a la habilidad que desarrolla para este tipo de relaciones, y a su posición social por ser descendiente de una de las ramas más populares de los Villega. El trabajo con el carro se constituye en una siempre presente posibilidad de garantizar un ingreso económico que permita sostener una familia para aquellos chicos que ya son padres y se han estabilizado en una pareja. Sin embargo, para quienes han construido su masculinidad a través del reconocimiento comunitario, así como del autoreconocimiento como choros o chicos que andan en la calle, las tareas en el carro implican la posibilidad del deshonor y cuestionamiento al estatus ganado hasta entonces. Talo, hermano de Maco, expresaba su rechazo a salir en el carro como se lo proponían sus tíos y hermanos mayores debido a que esto le producía vergüenza $a^{41}$. Finalmente Talo comienza a trabajar en el carro de su hermano, respondiendo más a los consejos de sus

\footnotetext{
39 Estos eran los costos que Maco manejaba en Noviembre de 2006.

40 Hacer cagar a alguien: pegarle.

41 Pitt-Rivers ha definido la "vergüenza" "como un interés por la reputación, a la vez un sentimiento y el reconocimiento público de ese sentimiento. Es aquello que hace a una persona sensible a la presión ejercida por la opinión pública." (1968: 42)
}

primos y tíos, y priorizando el ser un padre que es capaz de sacrificar la honra que regía en su grupo de amigos para poder mantener económicamente a su hijo de siete meses de edad. Talo viene a representar la posibilidad de sostener ambas o bien intercalar estas actividades: laburar en el carro y salir a robar, ya que tampoco ha abandonado esta última. La posición privilegiada de Talo dentro del grupo de hermanos y primos con quienes comparte una posición generacional, le permite alternar entre estos ámbitos de trabajo ${ }^{42}$ no perder estatus ni prestigio en ello.

La construcción de la masculinidad a través de estas dos actividades no se da de modo dicotómico, sino que un mismo chico puede desarrollarse en el laburo en el carro y no por ello abandonar otras experiencias que también implican una demostración de virilidad y de búsqueda de respeto en las relaciones sociales. Más allá de su generización a través del laburo en el carro, Maco hace uso y ostentación de su cuerpo para pararse ante otros en diversas situaciones, delimitando así hasta donde se llega y hasta donde no se debe llegar en la interacción con él:

Me habían contado que Maco había roto los vidrios del auto de unos hombres que pasaron por allí. Al preguntarle a él qué fue lo que sucedió me cuenta que estos hombres eran conocidos y que estaban tomando unas cervezas con ellos cuando uno de éstos tiró una botella justo al lado de donde estaba la hija menor de Maco. La botella explotó al caer y los vidrios que saltaron lastimaron la pierna de ésta. Si la tiraban justo encima la mataban..., expresaba Maco al mostrarse sumamente disgustado por ello. Me cuenta que por tanto él tomó un par de piedras y se las tiró a los parabrisas del auto, rompiendo éstos en mil pedazos.

Reacciones como la de Maco son codificadas en la villa dentro de lo esperable y valorado para un hombre que viva una situación de violencia hacia su familia. Para entender esto tomo a Gilmore (1999), quien presenta estudios sobre prácticas sociales que implican un esfuerzo de conquista a esta categoría de ser hombre. El autor define a la masculinidad como "la forma aceptada de ser un varón adulto en una sociedad concreta." Este hacerse hombre debe conquistarse con mucho esfuerzo y constituye un premio que puede ser alcanzado a través de ciertos ritos, ciertas prácticas e instancias de pruebas de quienes son aptos para ser considerados 'verdaderos hombres'. Cuando Gilmore hace referencia al esfuerzo que implica adquirir la condición cultural de 'hombre' (legitimada socialmente), está haciendo referencia en realidad a la necesaria demostración cotidiana de su virilidad que se le exige socialmente al hombre, por más naturalizada que se viva.

\footnotetext{
42 Salir a robar es significado por estos chicos como un trabajo, dentro del cual reconocen los riesgos que este implica para sí mismos como para las víctimas, pero a través del cual han aprendido a garantizarse un modo de obtener ingresos y un modo de construirse en una masculinidad legitimada socialmente en su entorno próximo.
} 
Por su parte, para las mujeres no es 'bien visto' que anden en el carro, y es así que las parejas, hijas, hermanas de estos jóvenes no suben ni salen en el carro salvo raras excepciones. Hablando con Luciana respecto los cambios que ha vivido entre aquellas cuestiones que realizaba cuando era más chica y qué cosas hace ahora me comenta:

Luciana: jahora ni loca me subo al carro de mi hermano...!

M: ¿y por qué no?

Luciana: porque me da vergüenza...

$\mathrm{M}$ : ¿y cuándo sí lo hacías?

Luciana: cuando era más chica...

Cuando hay tensiones en las relaciones entre hermanas y/o cuñadas el que alguna de ellas se haya subido al carro de su marido o hermano puede funcionar como objeto de acusación y desprestigio entre unas y otras. En mi caso, salir en el carro con los chicos implicaba una interesante oportunidad de conocer en mayor profundidad sus formas de trabajar y andar en él. Verme andar en el carro provoca asombro para otras chicas que entonces comentan: jla Malena anda en el carro, no tiene problema!.

Así, a través de estos modos de vincularse con el carro, los varones se sienten reconocidos en la comunidad, mientras que las mujeres se muestran distanciadas de ello. Unos y otros apelan a distintas situaciones y recursos que a su vez son sostenidos y puestos a disposición de manera comunitaria.

\section{Poner el cuerpo y enfrentar a los del Marqués.}

Otro de los modos a través de los cuales los chicos y las chicas construyen sus formas de masculinidad y feminidad es a través de los enfrentamientos con los chicos y chicas del Marques. No son sólo los enfrentamientos los que reafirman o construyen cierta masculinidad y feminidad, sino que los relatos sobre dichos incidentes son piezas claves en sí mismas dentro de este proceso:

Estábamos sentados en el piso, charlando con Talo y Lorena, en el lugar donde Talo suele juntarse con sus amigos. Se acerca su primo Pablo, con quienes comienzan a comentar el enfrentamiento que acababan de protagonizar con un grupo de chicos del Marques ${ }^{43}$. Debatían la posibilidad de ir nuevamente hacia aquel lugar a continuar lo que habían comenzado. Lorena, mientras se reía, preguntaba: ¿quién tiene los fierros ${ }^{44}$ ?

\footnotetext{
43 Se trataba de un sector de barrio Marques de Sobremonte anexo al que llaman el pueblito y con quienes se han vivenciado diversos tipos de alianzas y rivalidades a lo largo de los últimos 10 años, pero con quienes diversas generaciones de la villa sostienen una rivalidad que precede a la generación de Talo y sus hermanos y amigos.

${ }^{44}$ Con la palabra fierro hacen referencia a las armas de fuego.
}

Pablo: jsi no te digo que una vieja nos batido la cana ${ }^{45}$ ! Pablo maldecía contra la vieja que los había delatado a la policía y contaba que la yuta se llevó los fierros.

Talo: ¿se llevaron a alguien los cobani?

Pablo recordaba eufórico aquel incidente mientras daba detalles a sus amigos de las situaciones que éstos no presenciaron. Para esto, utilizaba todo su cuerpo, expresando con él cómo 'se les había parado' a aquellos chicos del Marques. De pie, con las piernas un tanto separadas, la pelvis levemente hacia delante y los brazos separados del cuerpo, representaba aquello que les decía a sus rivales: iqué te hacés el bobina ${ }^{46}$ vos!, a lo que le respondieron: iporque acá vivo yo!

A medida que avanzaba en el relato, Pablo hacía cada vez más ostentación de cómo fue capaz de enfrentarse a la posibilidad de que le disparen, sin mostrar temor al respecto. Se levantó la remera, recreando la escena de la que había sido protagonista, y decía: jdale, tirá, tirá y listo! ¡Y sentí que la bala pasaba por el costado!

Talo y Lorena escuchaban fascinados la reconstrucción de Pablo. Ella los alentaba a que vayan nuevamente a enfrentar a 'los chicos del pueblito', pero Pablo le recordaba: jno ves que la mina esa nos batió la cana!

Lorena: ipor eso, si ya está, si ya te fichó la cana, qué te importa ahora!

Cuando un grupo de jóvenes es desafiado por otro en su propio barrio ambos grupos se encuentran ante la posibilidad de poner en cuestión el honor del grupo rival, ya sea por ser enfrentados en su propio barrio o bien por ser capaz de sostener el desafío de pelear en territorio ajeno. Es así que a través de estos enfrentamientos o amenazas de ellos, los chicos tienen la posibilidad de mostrarse y ser reconocidos en tanto iguales con quienes rivalizan, con capacidad de implicar un desafío para el otro y posicionarse así lo más lejos posible del riesgo de caer en la ignorancia o el desvalor que implica ser denigrados por la opinión pública (Bourdieu, 1968). Tomando las descripciones de Bourdieu para la sociedad de Cabilia, encontramos para este caso cómo estos combates que protagonizan los chicos adquieren lo que el autor describe de la siguiente manera:

"la forma de un juego estrictamente reglamentado, de una competición ordenada, que, lejos de amenazar el orden social, tendía, al contrario, a salvaguardarlo, permitiendo que el espíritu competitivo, el pundonor, el nif47, se manifestase, pero en

\footnotetext{
45 Batir la cana: denunciar o dar aviso a la policía.

46 Bobina es una expresión de uso corriente en los chicos y chicas y su significado va variando en las distintas situaciones y personas en cuestión. En la situación aquí descripta hace referencia a alguien que intenta mostrar valor, que tiene agallas.

47 “El sentimiento del honor se vive de cara a los demás. El nif, la
} 
formas prescritas e institucionalizadas." (Bourdieu, 1968: 182)

Cuando se busca confrontar con otros dentro del territorio de éstos, se los interpelará cuestionando su valentía y honor para poder presentarse 'tan vivos' como ellos, que se animan a poner el cuerpo aún estando 'de visitantes'.

El relato de Pablo muestra el efecto performativo de la situación de enfrentamiento que vivió así como de la reconstrucción mediante el relato a sus amigos. A través de la misma él deviene en un chico que tiene calle, que tiene valentía y capacidad de violencia ante posibles nuevos enfrentamientos, y así también va construyendo su cuerpo como un cuerpo masculino que se presenta sin temor ante los posibles riesgos ${ }^{48}$ que esto implica. Estas prácticas con uso de violencia, una violencia ritualizada y en algún punto posible de preverse, adquieren un valor positivo y se presentan como legítimamente constructoras de subjetividades masculinas ${ }^{49}$.

La construcción de los cuerpos de los chicos se va forjando así, a través de estos modos de usar, presentar y construirlos en aquellas interacciones. Entiendo los recorridos en el robo que desarrollan algunos jóvenes como parte de prácticas performativas a través de las cuales se construyen subjetividades legitimadas en el marco de las relaciones sociales en la villa.

Quien actualmente oficia de 'mediador' entre agentes del gobierno y la gente de la villa, se mostraba firmemente convencido de que si a los chicos se les ofreciera un trabajo para ocupar su tiempo éstos dejarían el choreo. Seguido de esto comenta lo siguiente: si vos los ves que si están así y hay una chica más allá enseguida empiezan a decir que chorean... Y las chicas también, porque yo hablo mucho con las chicas, y vos vez que si viene un chico asi a hablarles y que les dice que estudia, que tiene trabajo, ellas no le dan ni bola, en cambio sí les gusta el que anda choreando, que anda armado, eso...

estima de sí mismo, es ante todo el hecho de defender, a cualquier precio, cierta imagen de sí mismo destinada a los demás." (Bourdieu, 1968: 189)

48 La Mendola (2005) plantea que el riesgo es una cuestión eminentemente juvenil debido a que los jóvenes con sus comportamientos exasperan y muestran los desafíos a los que en verdad nos enfrentamos todos como sociedad occidental en la actual fase histórica. No se podría reducir el asunto del riesgo a una cuestión psicopatológica ya que desconoceríamos así los factores en juego. Para este autor, las trayectorias en situaciones de riesgo son producto de la demanda que existe para afirmarse como personas autónomas y dotadas de poder. (La Mendola, 2005)

${ }^{49}$ Spagnol (2005) plantea cómo los grupos de jóvenes considerados gangues por los medios en Sao Paula utilizan la expresividad del cuerpo como una forma de lenguaje a través del cual se posicionan ante grupos de jóvenes de distintos sectores sociales con mayor o menor prestigio y poder. Este autor también encuentra que para estos jóvenes las actividades delictivas son un modo de encontrar placer a través de ellas, de sentir emoción no sólo al realizarla, sino en los relatos sobre dichas experiencias.
Así vive Damián ${ }^{50}$ este tener que resguardar su hombría a través del enfrentamiento violento con otros jóvenes: Constantemente están buscando lío los chicos. Y uno trata de defenderse así como sea para no tener problemas, pero por ahí te cansan demás y ya hay que ir a los hechos directamente. Tenemos que ir a los golpes, si no queda otra. Sino pasás por cobarde.

Otros trabajos etnográficos muestran una construcción de la masculinidad donde justamente esta se apoya en vivencias que tengan el uso de la fuerza y la violencia como mecanismos centrales para controlar o resolver una situación conflictiva o bien para demarcar límites entre los grupos, cohesionar a éstos y forjar sus identidades y alianzas grupales (Garriga Zucal, 2007; Serrano Amaya, 2004; Rossini, 2003; Kessler, 2002). De este modo, los intercambios con uso de la violencia física, o de la amenaza del uso de la misma se constituyen en fundamentales modos de construir lazos sociales particulares, y devienen en espacios de simbolización de las subjetividades de los jóvenes que se involucran en ellas. Las formas de violencia física entre grupos rivales y de amigos, no vendría a romper o destruir los vínculos, sino que instauran posiciones y jerarquías a través de las cuales los chicos y chicas configuran sus modos de ser.

\section{Las chicas: cuerpos, alianzas y rivalidades.}

En el caso de las chicas, si bien es menor la frecuencia con que se reúnen en espacios por fuera de sus casas, cuando lo realizan, también construyen alianzas con unas y rivalidades con otras. Estas diferencias también se observan a partir de gestos, miradas, modos de pararse y distanciarse físicamente, y categorías en el lenguaje que utilizan de manera preponderante en aquellas situaciones en las que en el encuentro con 'otras' se juegan sus posiciones y estatus en la comunidad.

Me encontraba saludando a Lara cuando veo que a cinco metros estaban tres chicas paradas. Desde aquel lugar me hacían insistentes señas para que me acerque hacia donde estaban ellas. Yo no entendía por qué me llamaban desde esa distancia en vez de acercarse ellas. Cuando me despido de Lara me acerco hasta allí y comprendo que lo que sucedía era que no querían acercarse a Lara por la fuerte aversión que sienten hacia ella. A pesar de la obviedad con que manifestaban este rechazo, Lara las ignoraba como ha hecho en otras oportunidades. Así es que les pregunto: ¿me parece a mi o ustedes no la quieren a Lara? Ellas responden haciendo gestos de desagrado y levantando los hombros. Insisto: ¿y por qué no la quieren?, y la respuesta fue claramente no sólo referida

\footnotetext{
50 Damián es un chico de 18 años, hermano de Maco por parte de madre. Durante su infancia compartía las andadas por la villa y sus alrededores con Talo. A medida que fueron creciendo sus caminos comenzaron a tomar sentidos diferentes y a frecuentar distintos grupos de amigos: Damián construyó relaciones de amistad en la escuela, mientras que Talo afianzó más los vínculos con primos y vecinos de la villa que tampoco concurrían más a la escuela.
} 
a Lara sino también a las chicas que componen el entorno de ésta: porque ellas se hacen las lindas. Cuando están solas asi nos Ilaman para que vayamos, y cuando están con sus amigas ni nos saludan.

Hacerse la lind $a^{51}$ es una de las peores cosas que puede hacer una chica si no quiere ganarse enemigas. Meli y Paola me cuentan cómo se han agarrado a piñas con un grupo de chicas del Marques porque ellas dicen que nosotras nos hacemos las lindas.

\section{$\mathrm{M}$ : ¿qué es hacerse la linda?}

Paola: $y$... porque llevamos unas zapatillas así lindas... por eso...

Hacerse la linda no es tanto algo que una chica haga de modo diferente a las otras, sino más bien es el calificativo que éstas utilizan para poder acusarla de algo que - por lo menos dentro del poderoso círculo de rumores femeninos - la coloque en posición desfavorable, la desprestigie y tal vez así disminuya en parte el nivel de competencia que ésta representa en el mercado de chicos disponibles. Meli y Paola ostentan así entre sus pares que ellas no dejarán pasar aquella acusación y pelearán también por el honor cuestionado por las del Marques. Si bien los rumores que puedan circular por estos enfrentamientos no las posicione de manera favorable para muchos adultos, sí les garantiza, en el marco de las relaciones entre los chicos y chicas de su generación, cierta fama de ser chicas que saben andar en la calle y que no se amedrentarán ante futuras posibles rivales.

\section{Conclusiones}

Las interacciones con frecuente apelación a la violencia atraviesan los procesos de sociabilidad y de constitución de la propia subjetividad tanto en los niños como en los jóvenes y adultos de la villa. Estos modos de vinculación con 'el otro' los constituye al mismo tiempo como 'verdaderos varones' y como 'chicas con poder y prestigio', y los integra dentro de un grupo de amigos/as donde comparten códigos corporales, de lenguaje, vestimenta, y les otorga herramientas para afrontar las diferentes situaciones de interacción con otros más lejanos o cercanos. Por lo que estas prácticas, construidas socialmente, implican performances que hacen a la misma seguridad psíquica y social de los chicos, chicas, hombres y mujeres de villa El Nailon.

A lo largo de este trabajo he encontrado en los modos culturalmente instaurados y socialmente aceptados en villa El Nailon de devenir varones, de construirse subjetivamente hombres desde cierta masculinidad

\footnotetext{
51 Ver la descripción y análisis que Blázquez (2006) realiza de las categorías de clasificación que se construyen en sectores populares de Córdoba, donde desde una posición autoreferencial y de construcción de 'normalidad,' quien enuncia presenta y construye a las otras como 'una humienta' o una 'negra' según el sistema de diferenciación que opera en cada contexto social y de interacción.
}

presentada como hegemónica, un camino para entender estas relaciones entre generaciones, entre hermanos, entre familias, y las prácticas que los chicos realizan en su vida cotidiana. Quienes ya tienen más de 24 años aproximadamente, se presentan como modelo del ser varón socialmente valorado en la villa. Muchas veces esta forma de alcanzar una masculinidad legitimada implica mostrarse potencialmente violento, con capacidad de asumir riesgos, con experiencia en la calle, en el fútbol, en el choreo, etc.; mientras que para las chicas implica saber con quiénes, por dónde y cómo moverse. Las distintas trayectorias de vida por las que transitan chicos y chicas y las posiciones y relaciones que van construyendo en el entramado de su red parental, va configurando ciertos modos de devenir hombres y mujeres. Revalorizando en algunos casos el fútbol, en otros el trabajo, en otros el choreo o bien atravesando una intrincada combinación de todos ellos, los varones devienen genéricamente hombres. Por su parte, las chicas van transitando por espacios de diferenciación y simbolización de lo que significa devenir una mujer en la villa, donde constantemente negocian y disputan, con mayor o menor fuerza puesta en ello, los márgenes de posibilidades que tendrán para revertir las lógicas, prohibiciones y normativas impuestas implícita o explícitamente sobre cuáles son los modos legitimados y permitidos de constituirse subjetivamente en villa El Nailon.

Así como estos modos comunitarios y familiares de configurar los tránsitos por los espacios y las relaciones que en ellos se producen van construyendo los cuerpos y las subjetividades de los jóvenes de la villa, así también estas inscripciones en los cuerpos y personalidades encuentran en el entrecruzamiento de historias familiares, individuales, sociales y comunitarias, las posibilidades para nuevos reposicionamientos que configuren dinámicas particulares así como la reactualización y renovación de una tradición anclada en la transmisión intergeneracional.

\section{Bibliografía}

Blázquez, G. 2008 Nosotros, vosotros y ellos: Las poéticas de las Masculinidades Heterosexuales entre jóvenes cordobeses. TRANS Revista Transcultural de Música. Julio. $N^{\circ} 12$. Sociedad de Etnomusicología. Barcelona España. http://redalyc.uaemex.mx/redalyc/src/inicio/ArtPdfRed. jsp?iCve=82201206

Blázquez, G. 2006 Y me gustan los bailes... Haciendo género a través de la danza de cuarteto cordobés. Etnografías contemporáneas. Año 2, número 2. Buenos Aires: Universidad Nacional de San Martín.

Bourdieu, P. 1968 El sentimiento del honor en la sociedad de Cabilia. En Peristiany, J. G. (1968) El concepto de honor en la sociedad mediterránea. Barcelona: Ed. Laborsa.

Butler, J. 2002 Cuerpos que importan. Sobre los límites materiales y discursivos del "sexo". Introducción. Buenos 
Aires. Paidós.

Butler, J. 2001 [1999] El Género en disputa. El feminismo y la subversión de la identidad. Prefacio de. México: Ed. Paidós.

Corrigan, P. 1982 [1976] Doing nothing en Hall, Stuart y Jefferson, Tony (eds.) Resistance through rituals. Youth subcultures in post-war Britain. London: Hutchinson.

Descolá, P. 2005 [1993] Las lanzas del crepúsculo. México: FCE.

Garriga Zucal, J. 2007 Haciendo amigos a las piñas. Violencia y redes sociales de una hinchada del fútbol. Buenos Aires: Prometeo Libros.

Gilmore, D. 1999 Hacerse hombre. Ataya, Madrid, .

Gutiérrez, A. 2002 La organización de lo cotidiano en familias de un Barrio pobre cordobés. En Falú, Morey y Rainero (eds.) Ciudad y Vida cotidiana. Asimetrías en el uso del tiempo y del espacio. Córdoba: Falú, Morey y Rainero editoras.

Jelin, E. 2006 [1998] Pan y afectos. La transformación de las familias. Buenos Aires: Fondo de Cultura Económica.

Kessler, G. 2002 Sociología del delito amateur. Buenos Aires: Paidós.

La Mendola, S. 2005 O sentido do risco, en Tempo Social, revista de sociología da USP. Vol. 17 n² 2. Nov. de 2005.

Pitt-Rivers, J. 1968 Honor y categoría social en Peristiany, J. G. (1968) El concepto de honor en la sociedad mediterránea. Barcelona: Ed. Laborsa.

Rodigou, M. 2002 Vida cotidiana, trabajo y espacio barrial. Significaciones diferenciales de varones y mujeres de dos sectores socioeconómicos. En Falú, Morey y Rainero (eds.) Ciudad y Vida cotidiana. Asimetrías en el uso del tiempo y del espacio. Córdoba: Falú, Morey y Rainero editoras.

Rossini, G. (2003) Vagos, pibes chorros y transformaciones de la sociabilidad en tres barrios periféricos de una ciudad entrerriana."En Isla, Alejandro y Míguez, Daniel (2003) Heridas Urbanas. Buenos Aires: Editorial de las Ciencias.

Rotondi, G. 2000 Pobreza y masculinidad. El urbano marginal. Córdoba: Espacio editorial.

Serrano Amaya, J. F. 2004 Menos querer más de la vida. Concepciones de vida y muerte en jóvenes urbanos. Colombia: Siglo del Hombre Editores.

Spagnol, A. S. 2005 "Jovens delinquentes paulistanos". En Tempo Social, revista de sociología da USP. Vol. $17 \mathrm{n}^{\circ}$ 2. Nov. de 2005.

Spósito, M. P. 1994 A sociabilidade juvenil e a rua. Revista Tempo Social. Vol. 5 - Nº 1 - 2. 1993- (1994) 
